\title{
Substratos no enraizamento de estacas herbáceas de amora-preta Xavante
}

\author{
Substrates on rooting of blackberry Xavante herbaceous cuttings
}

\author{
Lilian Yukari Yamamoto ${ }^{\mathrm{I}}$ Renata Koyama ${ }^{\mathrm{I}}$ Wellington Fernando Silva Borges ${ }^{\mathrm{II}}$ \\ Luís Eduardo Corrêa Antunes ${ }^{\mathrm{III}}$ Adriane Marinho de Assis ${ }^{\mathrm{IV}}$ Sérgio Ruffo Roberto ${ }^{\mathrm{V}}$
}

RESUMO

A amora-preta (Rubus spp.) destaca-se entre as espécies que apresentam boas perspectivas de cultivo em áreas de agricultura familiar. Visando a otimizar a multiplicação de mudas dessa espécie, o objetivo deste trabalho foi avaliar o uso de substratos e concentrações do ácido indolbutírico (AIB) no enraizamento de estacas de amora-preta Xavante. O delineamento experimental foi o inteiramente casualizado em arranjo fatorial $3 \times 2$ (três tipos de substratos e duas concentrações de AIB), com cinco repetições de sete estacas, sendo adotados os fatores: tipos de substratos (casca de arroz carbonizada, vermiculita grânulos médios e fibra de coco) $e$ tratadas ou não com AIB (0 e 1000mg $\left.\mathrm{L}^{-1}\right)$. Após 80 dias, foram avaliadas as variáveis: sobrevivência das estacas; retenção foliar; estacas enraizadas; número de raízes por estaca; comprimento da maior raiz; massa seca das raízes por estaca; e pH; condutividade elétrica; densidade e capacidade de retenção de água dos substratos. Não houve influência dos substratos e da aplicação de AIB sobre a porcentagem de estacas enraizadas, verificando-se alta eficiência no enraizamento das estacas de amora-preta Xavante (86,2\%). Para a porcentagem de sobrevivência das estacas, o melhor resultado foi obtido sem a aplicação de AIB. Conclui-se que a amora-preta Xavante pode ser propagada por estaquia herbácea com eficiência, sem o uso de AIB, utilizando-se preferencialmente o substrato casca de arroz carbonizada como opção de baixo custo.

Palavras-chave: propagação, ácido indolbutírico, regulador de crescimento, Rubus sp.

\begin{abstract}
The blackberry (Rubus spp.) stands out among the species that have good prospects for cultivation in areas of family farm agriculture. In order to optimize the multiplication of seedlings of this species, the aim of this research was to evaluate the use of different substrates and concentrations of indolebutyric acid (IBA) on the rooting of cuttings of blackberry Xavante. The experiment was performed using the completely randomized design in a $3 \times 2$ factorial arrangement (three substrates and two concentrations of IBA), with five replications of seven cuttings, and the following factors were adopted: types of substrates (vermiculite medium granules, carbonized rice husk and coconut fiber) and treated or not treated with IBA (O and 1000mg $\mathrm{L}^{-1}$ ). After 80 days, the following variables were evaluated: cuttings survival; leaf retention; rooted cuttings; root number per cutting; length of the longest root; dry weight of roots per cutting; and $\mathrm{pH}$; electrical conductivity; bulk density and water retention capacity of the substrates. There was no influence of the substrates and the IBA on the percentage of rooted cuttings, verifying the high efficiency on rooting of the blackberry Xavante cuttings (86.2\%). For the percentage of cuttings survival the best result was obtained without the IBA application. It was concluded that the blackberry Xavante can be propagated by herbaceous cuttings efficiently, using the carbonized rice husk as low-cost option.
\end{abstract}

Key words: propagation, indolebutyric acid, growth regulators, Rubus sp.

\footnotetext{
'Programa de Pós-graduação em Agronomia, Centro de Ciências Agrárias (CCA), Universidade Estadual de Londrina (UEL), Londrina, PR, Brasil.

IICurso de Agronomia, UEL, Londrina, PR, Brasil.

IIIPrograma Nacional de Pós-doutorado, CCA, UEL, Londrina, PR, Brasil.

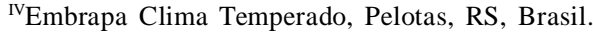

${ }^{\mathrm{v}}$ Departamento de Agronomia, UEL, CP 6001, 86051-990, Londrina, PR, Brasil. E-mail: sroberto@uel.br. Autor para correspondência.
} 


\section{INTRODUÇÃO}

Os pequenos frutos, como a amora-preta (Rubus spp.), a framboesa (Rubus spp.) e o mirtilo (Vaccinium spp.), estão entre as espécies que apresentam boas perspectivas de ampliação do cultivo e geração de renda em áreas de agricultura familiar, em função da necessidade de uso intensivo de mão-deobra e baixo índice de mecanização, além da aceitação do mercado consumidor, devido às suas propriedades nutracêuticas (PIO, 2008).

A cultivar de amora-preta 'Xavante' apresenta hastes vigorosas, eretas e sem espinhos, características estas de grande interesse, uma vez que possibilitam o menor custo de produção, por não necessitarem de suporte e facilitarem os tratos culturais e a colheita (RASEIRA et al., 2004).

Na propagação da amora-preta, podem ser usadas estacas herbáceas, lenhosas e de raízes, além dos rebentos e da cultura de tecidos (ANTUNES et al., 2004). Entretanto, a propagação por estaquia de raízes apresenta como desvantagem o número limitado de mudas, além do trabalho requerido para a obtenção das estacas. Por outro lado, embora a cultura de tecidos permita a produção de mudas em grande escala, tratase de um método oneroso, em função da necessidade de laboratório devidamente equipado e de mão-de-obra especializada (BEYL \& TRIGIANO, 2008).

O sucesso da propagação vegetativa por estaquia depende, além do potencial genético de enraizamento, das condições fisiológicas da planta matriz, da época do ano, do balanço hormonal, da temperatura, luz e umidade (FACHINELLO et al., 2005). O processo de formação de raízes em estacas também está relacionado ao substrato, que exerce influência na qualidade das raízes formadas e no percentual de enraizamento (KÄMPF et al., 2006; LONE et al., 2010b). Dessa forma, é fundamental a seleção de substratos que possibilitem a retenção de água suficiente para prevenir a dessecação da base da estaca e possuam espaço poroso, para facilitar o fornecimento de oxigênio, para a iniciação e desenvolvimento radicular. $\mathrm{O}$ material deve apresentar boa aderência à estaca e não conter substância fitotóxica à espécie (ANTUNES et al., 2004; FACHINELLO et al., 2005). Entre os materiais comumente usados estão a vermiculita, a casca de arroz carbonizada e a fibra de coco (ZIETEMANN \& ROBERTO, 2007; LONE et al., 2010b).

Para favorecer o desenvolvimento radicular, a utilização de reguladores de crescimento pode viabilizar a produção de mudas em espécies de difícil enraizamento (FACHINELLO et al., 2005). Dentre as auxinas sintéticas mais utilizadas no processo de estaquia, o ácido indolbutírico (AIB) é bastante efetivo para um grande número de espécies e relativamente estável, sendo pouco suscetível à ação dos sistemas de enzimas de degradação de auxinas, além de não ser tóxico à maioria das plantas (PIRES \& BIASI, 2003). No entanto, o efeito benéfico das auxinas exógenas varia entre espécies, cultivares e concentrações (VILLA et al., 2003; MAIA \& BOTELHO, 2008; LONE et al., 2010b).

Diante do exposto, o objetivo deste trabalho foi avaliar o uso de diferentes substratos e do AIB no enraizamento de estacas de amora-preta Xavante, visando a otimizar o sistema de produção de mudas.

\section{MATERIAL E MÉTODOS}

O experimento foi realizado no período de abril a julho de 2011, no Setor de Fruticultura do Centro de Ciências Agrárias da Universidade Estadual de Londrina (UEL) - PR (latitude $23^{\circ} 23 \mathrm{~S}$, longitude $51^{\circ} 11 \mathrm{O}$ e altitude de 566m), em condições controladas. Foram utilizadas estacas herbáceas de 10-12cm, retiradas da parte mediana dos ramos de plantas matrizes da amoreirapreta Xavante (Rubus sp.) com um ano, provenientes da Embrapa Clima Temperado, Pelotas-RS.

Odelineamentoexperimental foi o inteiramente casualizado, com cinco repetições de sete estacas em arranjo fatorial $3 \times 2$, sendo os fatores os três tipos de substratos (casca de arroz carbonizada, vermiculita de granulação média e fibra de coco padrão 47, Amafibra ${ }^{\circledR}$ ) e a aplicação ou não de $\operatorname{AIB}\left(0\right.$ e $\left.1000 \mathrm{mg} \mathrm{L}^{-1}\right)$.

Antes de efetuar a coleta das estacas, foi preparada a solução hidroalcoolica do AIB, segundo FACHINELLO et al. (2005), sendo pesados 0,1g de AIB e dissolvidos em $50 \mathrm{~mL}$ de álcool. Após totalmente dissolvido o AIB, o volume foi completado para $100 \mathrm{~mL}$, com água destilada, obtendo-se a concentração de $1000 \mathrm{mg} \mathrm{L}^{-1}$ de AIB.

O preparo das estacas consistiu em um corte em bisel logo abaixo de um nó, com a eliminação das folhas da parte basal, deixando-se dois pares de folhas na parte superior. Durante o preparo, as estacas foram dispostas em um recipiente com água para evitar a desidratação. Após o preparo das estacas, o AIB foi aplicado por meio de imersão rápida da base das estacas durante 10 segundos.

Em seguida, as estacas foram colocadas em caixas plásticas $(44 \times 30 \times 7 \mathrm{~cm})$ perfuradas para 
enraizamento, contendo os substratos, dispostas em câmara de nebulização com regime intermitente controlado por temporizador e válvula solenoide. A válvula foi programada para nebulizar durante 10 segundos a cada três minutos. O bico nebulizador empregado (Modelo Mist DanSprinklers, Israel) apresenta vazão de $35 \mathrm{~L} \mathrm{hora}^{-1}$. A câmara de nebulização foi inserida em estufa com cobertura de filme de polietileno transparente e sombrite $30 \%$.

Para o controle de doenças fúngicas, as estacas foram tratadas semanalmente com fungicidas a base de tebuconazole $\left(1 \mathrm{~mL} \mathrm{~L}^{-1}\right)$ por pulverização. Foi realizada, a cada 15 dias, adubação foliar com fertilizante Biofert Plus ${ }^{\circledast}$ (8-9-9 + micro) na concentração 5 $\mathrm{mL} \mathrm{L}^{-1}$ por pulverização. Durante a condução do experimento, as médias das temperaturas máximas e mínimas no interior da estufa foram de $27,1 \mathrm{e} 12,3^{\circ} \mathrm{C}$, respectivamente.

Após 80 dias da instalação do experimento, foram avaliadas as seguintes variáveis: sobrevivência das estacas (\% de estacas vivas); retenção foliar (\% de estacas que não perderam as folhas); estacas enraizadas (\% que emitiram pelo menos uma raiz); número de raízes por estaca; comprimento da maior raiz por estaca $(\mathrm{cm})$ e massa seca das raízes por estaca (g). A massa seca das raízes foi obtida por meio de secagem em estufa com circulação forçada de ar a $78^{\circ} \mathrm{C}$, por $48 \mathrm{~h}$. Foram avaliados o $\mathrm{pH}$ em água, na relação 1:1, a condutividade elétrica $\left(\mu \mathrm{S} \mathrm{cm}^{-1}\right)$, a densidade $\left(\mathrm{kg} \mathrm{m}^{-3}\right)$ e a capacidade de retenção de água $\left(\mathrm{mL} \mathrm{L}^{-1}\right)$ dos substratos, segundo KÄMPF et al. (2006).

Os dados foram submetidos à análise de variância e as médias comparadas pelo teste de Tukey, a 5\% de probabilidade. Foi efetuada a transformação de dados arco seno $\sqrt{\mathrm{x} / 100}$ para as variáveis oriundas de porcentagem e, para as variáveis oriundas de contagem, foi realizada a transformação $\sqrt{\mathrm{x}+1}$.

\section{RESULTADOS E DISCUSSÃO}

Não houve interação significativa entre os tipos de substratos e as concentrações de AIB para nenhuma das características de enraizamento, mostrando que os fatores estudados atuam de forma independente no processo de enraizamento.

Para a porcentagem de sobrevivência das estacas, não foi verificada diferença significativa entre os substratos (Tabela 1). ZIETEMANN \& ROBERTO (2007) não verificaram diferença quanto à porcentagem de sobrevivência de estacas de goiabeira (Psidium guajava L.), cv. 'Paluma' e 'Século XXI', utilizando os substratos casca de arroz carbonizada e vermiculita, tampouco entre as diferentes concentrações de AIB $(0 \mathrm{a}$ $\left.2000 \mathrm{mg} \mathrm{L}^{-1}\right)$. Em experimento realizado por SCHUCHet al. (2007), a porcentagem de sobrevivência das microestacas de mirtilo Climax foi superior no substrato Plantmax $^{\circledR}$ em relação à areia. PELIZZA et al. (2011), ao avaliarem a mesma cultivar de mirtilo, também observaram que a mistura do substrato Plantmax ${ }^{\circledR}$ e casca de arroz carbonizada apresentou resultados satisfatórios no processo de enraizamento das microestacas.

Quanto à porcentagem de retenção foliar, não houve diferença entre os substratos e a aplicação ou não de AIB (Tabela 1). De acordo com HARTMANN et al. (2002), a presença de folhas nas estacas influencia

Tabela 1 - Sobrevivência das estacas, retenção foliar e brotação de amora-preta Xavante (Rubus sp.), submetidas aos diferentes substratos e às concentrações de ácido indolbutírico (AIB). Londrina, PR, 2011.

\begin{tabular}{lccc}
\hline Tratamento & Sobrevivência das estacas (\%) & Retenção foliar (\%) & Brotação (\%) \\
\hline Concentrações de AIB $\left(\mathrm{mg} \mathrm{L}^{-1}\right)$ & & & \\
0 & $94,3 \mathrm{a}$ & $36,2 \mathrm{~ns}$ & $93,3 \mathrm{~ns}$ \\
1000 & $85,7 \mathrm{~b}$ & 30,5 & 85,7 \\
Média & 90,0 & 33,4 & 89,5 \\
Substrato & & & \\
CAC & $94,3 \mathrm{~ns}$ & $28,6 \mathrm{~ns}$ & $94,3 \mathrm{~ns}$ \\
VERM & 87,1 & 32,9 & 85,7 \\
FCOCO & 88,6 & 38,6 & 88,6 \\
Média & 90,0 & 33,4 & 89,5 \\
CV $(\%)$ & 18,34 & 44,46 & 18,35 \\
\hline
\end{tabular}

Médias seguidas das mesmas letras nas colunas não diferem entre si pelo teste de Tukey $(P<0,05)$. ns: não significativo. CAC: Casca de arroz carbonizada; VERM: Vermiculita - grânulos médios; FCOCO: Fibra de coco.

Ciência Rural, v.43, n.1, jan, 2013. 
no enraizamento, uma vez que a auxina é produzida nas folhas novas e nas gemas, sendo carreada com açúcares e outras substâncias nutritivas para a parte inferior da planta e acumulando-se na base do corte. Apesar da baixa porcentagem de retenção foliar $(33,4 \%)$, verificase que este fator não foi limitante para o enraizamento da amora-preta Xavante.

Em relação à porcentagem de brotação nas estacas, observa-se que não houve diferença entre os fatores estudados (Tabela 1). Para as estacas herbáceas do porta-enxerto de videira VR 43-43 (Vitis vinifera $\mathrm{x}$ Vitis rotundifolia), LONE et al. (2010a) não observaram diferença entre a casca de arroz carbonizada e a vermiculita para a porcentagem de brotação, obtendo maior porcentagem sem a aplicação de AIB. Resultados semelhantes a este trabalho foram relatados por MAIA \& BOTELHO (2008), que avaliaram o enraizamento de estacas lenhosas da amora-preta Xavante em diferentes concentrações de $\operatorname{AIB}\left(0\right.$ a $\left.3000 \mathrm{mg} \mathrm{L}^{-1}\right)$. Em estudo com estacas lenhosas de amora-preta Brazos e Guarani, VILLA et al. (2003) verificaram a redução na porcentagem de estacas brotadas da cultivar Brazos quando tratadas com AIB, enquanto, para a Guarani, a aplicação de AIB propiciou o incremento na porcentagem de estacas brotadas.

No que diz respeito à porcentagem de estacas enraizadas, não houve diferença entre os diferentes substratos e a aplicação de AIB, verificandose alta eficiência no enraizamento das estacas herbáceas de amora-preta Xavante (86,2\%) (Tabela 2). Em experimento realizado com estacas de goiabeira, ZIETEMANN \& ROBERTO (2007) não verificaram diferença para a porcentagem de enraizamento das estacas da cv. 'Paluma' nos substratos casca de arroz carbonizada e vermiculita. Para a cv. 'Século XXI', os mesmos autores observaram que o susbstrato casca de arroz carbonizada favoreceu esta variável. LONE et al. (2010a) também não verificaram diferença entre os substratos casca de arroz carbonizada e a vermiculita para porcentagem de estacas enraizadas do portaenxerto de videira VR 43-43.

Pelos resultados, é suposto que estacas herbáceas desta cultivar apresentam conteúdo de auxina endógena suficiente para promover o desenvolvimento de raízes adventícias, não necessitando, portanto, de aplicação de reguladores para esse fim. Em estudo com estacas lenhosas da mesma cultivar, MAIA\& BOTELHO (2008) verificaram que a concentração estimada de AIB para a maior porcentagem de enraizamento foi de $1826 \mathrm{mg} \mathrm{L}^{-1}$, correspondendo a 59,7\% de enraizamento. Segundo BEYL\& TRIGIANO (2008) e HARTMANN et al. (2002), estacas herbáceas de algumas espécies não necessitam de auxina exógena para a formação de raízes adventíceas. VILLA et al. (2003), ao avaliarem o enraizamento das estacas lenhosas de amora-preta, observaram que houve redução da porcentagem de estacas enraizadas da cultivar 'Brazos' quando tratadas com AIB, enquanto, para a Guarani, a aplicação de $2000 \mathrm{mg} \mathrm{L}^{-1}$ de AIB promoveu os melhores resultados. Resultados semelhantes foram relatados por ANTUNES et al. (2000) e FISCHER et al. (2008), que, ao avaliarem estacas de amora-preta e mirtilo, respectivamente, concluíram que o potencial de enraizamento é influenciado pela cultivar.

Tabela 2 - Estacas enraizadas, número de raízes por estaca, comprimento da raiz e massa seca de raízes por estaca de amora-preta Xavante (Rubus sp.), submetidas aos diferentes substratos e às concentrações de ácido indolbutírico (AIB). Londrina, PR, 2011.

\begin{tabular}{lcccc}
\hline Tratamento & $\begin{array}{c}\text { Estacas enraizadas } \\
(\%)\end{array}$ & $\begin{array}{c}\text { Número de raízes por } \\
\text { estaca }\end{array}$ & $\begin{array}{c}\text { Comprimento da raiz } \\
(\mathrm{cm})\end{array}$ & $\begin{array}{c}\text { Massa seca de raízes por } \\
\text { estaca }(\mathrm{g})\end{array}$ \\
\hline Concentrações de AIB $\left(\mathrm{mg} \mathrm{L}^{-1}\right)$ & & & & $0,6 \mathrm{~ns}$ \\
0 & $89,5 \mathrm{~ns}$ & $11,9 \mathrm{~ns}$ & $7,2 \mathrm{~ns}$ & 0,6 \\
1000 & 82,9 & 12,3 & 7,0 & 0,6 \\
Média & 86,2 & 12,1 & 7,1 & $0,6 \mathrm{~ns}$ \\
Substrato & & & 0,6 \\
CAC & $88,6 \mathrm{~ns}$ & $10,7 \mathrm{~ns}$ & 0,7 \\
VERM & 85,7 & 13,9 & $6,8 \mathrm{~ns}$ & 0,6 \\
FCOCO & 84,3 & 11,8 & 7,3 & 5,3 \\
Média & 86,2 & 12,1 & 7,1 & 59,92 \\
CV $(\%)$ & 20,07 & 17,58 & 28,95 & \\
\hline
\end{tabular}

ns: não significativo pelo teste de Tukey $(P<0,05)$.

CAC: Casca de arroz carbonizada; VERM: Vermiculita - grânulos médios; FCOCO: Fibra de coco. 
Quanto ao número, comprimento e massa seca das raízes, não houve diferença entre os substratos e o uso de AIB (Tabela 2). Em estudo com estacas de goiabeira cv. 'Século XXI', ZIETEMANN \& ROBERTO (2007) descreveram maior número e comprimento da raiz na casca de arroz carbonizada em relação à vermiculita, não verificando diferença entre os substratos para a massa seca das raízes. Com relação à aplicação de AIB, esses autores verificaram que a aplicação favoreceu o número e a massa seca de raízes por estaca, não influenciando no comprimento das raízes. Avaliando o enraizamento de estacas lenhosas da amora-preta Xavante, MAIA \& BOTELHO (2008) relataram que a aplicação de AIB não influenciou no comprimento médio de raízes e no número de raízes.

Com relação às características químicas dos substratos, as maiores médias de $\mathrm{pH}$ foram verificadas na vermiculita, diferindo significativamente da casca de arroz carbonizada (Tabela 3). Embora tenham sido observadas diferenças no $\mathrm{pH}$ dos substratos, o mesmo não influenciou no processo de enraizamento das estacas. Pode-se inferir que tal fato tenha ocorrido em função do curto período (80 dias) em que as estacas permaneceram no leito de enraizamento.

Quanto à condutividade elétrica, valores superiores foram constatados na fibra de coco (Tabela 3). SegundoHARTMANN et al. (2002) eBEYL\&TRIGIANO (2008), materiais que apresentam alta concentração salina (acima de $2500 \mu \mathrm{S} \mathrm{cm}^{-1}$ ) não são recomendados, podendo causar a redução do crescimento, a queima das folhas ou até mesmo a morte da planta. A condutividade elétrica ideal para substratos na propagação comercial de plantas está na faixa de 80 a 200 $\mathrm{S} \mathrm{cm}^{-1}$. HARTMANN et al. (2002) relataram que há uma grande variação no nível de tolerância à salinidade entre as espécies, sendo que a amora-preta apresenta baixa tolerância. No presente experimento, a condutividade elétrica variou entre 48,8 e
$119,2 \mu \mathrm{S} \mathrm{cm}^{-1}$, registrando-se valores abaixo do recomendado no substrato vermiculita $\left(48,8 \mu \mathrm{S} \mathrm{cm}^{-1}\right)$, no entanto, não houve influência desse fator no enraizamento das estacas.

Em relação às propriedades físicas dos substratos, as maiores médias quanto à densidade foram constatadas na casca de arroz carbonizada e na vermiculita. Por outro lado, para a capacidade de retenção de água, a maior média foi observada na fibra de coco (Tabela 3). FACHINELLO et al. (2005) descreveram que o efeito do substrato, tanto sobre o percentual de enraizamento, como sobre a qualidade das raízes formadas relaciona-se com a porosidade, que afeta o teor de água retida no substrato e, consequentemente, a aeração. De acordo com KÄMPF et al. (2006), os valores mais elevados de densidade podem representar maior resistência à expansão das raízes no substrato, além desses materiais exigirem bancadas mais firmes durante o cultivo e maior força física para o transporte dos recipientes.

Diante do exposto, verifica-se que a amorapreta Xavante pode ser propagada por estaquia herbácea, em todos os substratos testados, sem o uso de AIB, o que permite a redução do custo de produção. No entanto, dentre os substratos estudados, a casca de arroz carbonizada destaca-se como opção de baixo custo nas regiões com disponibilidade deste material, além de contribuir com a redução desse resíduo no meio ambiente.

\section{CONCLUSÃO}

A amora-preta Xavante pode ser propagada por estaquia herbácea com eficiência, sem o uso de AIB, utilizando-se preferencialmente o substrato de menor custo, entre os estudados.

Tabela 3 - pH, condutividade elétrica (CE), densidade e capacidade de retenção de água (CRA) dos substratos, aos 80 dias da instalação do experimento. Londrina, PR, 2011.

\begin{tabular}{llccc}
\hline Substratos & $\mathrm{pH}$ & $\mathrm{CE}\left(\mu \mathrm{S} \mathrm{cm}^{-1}\right)$ & Densidade $\left(\mathrm{kg} \mathrm{m}^{-3}\right)$ & $\mathrm{CRA}_{\left(\mathrm{mL} \mathrm{L}^{-1}\right)}$ \\
\hline CAC & $6,8 \mathrm{~b}$ & $88,8 \mathrm{~b}$ & $186,7 \mathrm{a}$ & $600,5 \mathrm{~b}$ \\
VERM & $7,1 \mathrm{a}$ & $48,8 \mathrm{c}$ & $183,9 \mathrm{a}$ & $486,9 \mathrm{c}$ \\
FCOCO & $6,9 \mathrm{ab}$ & $119,2 \mathrm{a}$ & $109,1 \mathrm{~b}$ & $816,7 \mathrm{a}$ \\
CV $(\%)$ & 3,03 & 16,95 & 19,07 & 9,36 \\
\hline
\end{tabular}

Médias seguidas das mesmas letras minúsculas nas colunas não diferem entre si pelo teste de Tukey $(P<0,05)$.

CAC: Casca de arroz carbonizada; VERM: Vermiculita - grânulos médios; FCOCO: Fibra de coco. 


\section{REFERÊNCIAS}

ANTUNES, L.E.C. et al. Propagação de cultivares de amoreirapreta (Rubus spp) através de estacas lenhosas. Revista Brasileira de Fruticultura, Jaboticabal, v.22, n.2, p.195-199, 2000.

ANTUNES, L.E.C. et al. Propagação, plantio e tratos culturais. In: ANTUNES, L.E.C.; RASEIRA, M.C.B. Aspectos técnicos da cultura da amora-preta. Pelotas: Embrapa Clima Temperado, 2004. 54p. (Embrapa Clima Temperado Documentos 122).

BEYL, C.A.; TRIGIANO, R.N. Plant propagation: concepts and laboratory exercises. Boca Raton: CRC, 2008. 462p.

FACHINELlO, J.C. et al. Propagação de plantas frutíferas. Brasília: Embrapa Informações Tecnológicas, 2005. 221p.

FISCHER D.L.O. et al. Efeito do ácido indolbutírico e da cultivar no enraizamento de estacas lenhosas de mirtilo. Revista Brasileira de Fruticultura, Jaboticabal, v.30, n.2, p.285-289, 2008. Disponível em: <http://www.scielo.br/scielo.php?pid=S0100$29452008000200003 \&$ script=sci_arttext $>$. Acesso em: 9 maio, 2011. doi: 10.1590/S0100-29452008000200003.

HARTMANN, H.T. et al. Plant propagation: principal and practices. 7.ed. New Jersey: Prentice Hall, 2002. 880p.

KÄMPF, A.N. et al. Floricultura: técnicas de preparo de substratos. Brasília: LK, 2006. 132p.

LONE, A.B. et al. Efeito do AIB no enraizamento de estacas herbáceas do porta-enxerto de videira VR 43-43 em diferentes substratos. Semina: Ciências Agrárias, Londrina, v.31, n.3, p.599-604, 2010a.

LONE, A.B. et al. Enraizamento de estacas de azaleia (Rhododendron simsii Planch.) no outono em AIB e diferentes substratos. Ciência Rural, Santa Maria, v.40, n.8, p.1720-1725, 2010b. Disponível em: <http://www.scielo.br/scielo.php?pid=S0103-847820 $10000800008 \&$ script=sci_arttext $>$. Acesso em: 10 abr. 2011. doi: 10.1590/S0103-84782010000800008.

MAIA, A.J.; BOTELHO, R.V. Reguladores vegetais no enraizamento de estacas lenhosas da amoreira-preta cv.
'Xavante'. Semina: Ciências Agrárias, Londrina, v.29, n.2, p.323-330, 2008. Disponível em: <http://www.uel.br/revistas/ uel/index.php/semagrarias/article/view/2823/2399>. Acesso em: 12 maio, 2011.

PELIZZA, T.R. et al. Microestaquia em mirtileiro com diferentes porções do ramo e substratos. Bragantia, Campinas, v.70, n.2, p.319-324, 2011. Disponível em: <http://www.scielo.br/pdf/brag/ v70n2/10.pdf $>$. Acesso em: 12 dez. 2011. doi: 10.1590/S000687052011000200010 .

PIO, R. O potencial de novas fruteiras. In: ENCONTRO DE FRUTICULTURA DOS CAMPOS GERAIS, 2008, Ponta Grossa, PR. Anais... Ponta Grossa: UEPG, 2008. p.11-21.

PIRES, E.J.P.; BIASI, L.A. Propagação da videira. In: POMMER, C.V. Uva: tecnologia da produção, pós colheita e mercado. Porto Alegre: Cinco Continentes, 2003. Cap.5, p.295-350.

RASEIRA, M.C.B. et al. Classificação botânica, origem e cultivares. In: ANTUNES, L.E.C.; RASEIRA, M.C.B. Aspectos técnicos da cultura da amora-preta. Pelotas: Embrapa Clima Temperado, 2004. 54p. (Embrapa Clima Temperado Documentos 122)

SCHUCH, M.W. et al. AIB e substrato na produção de mudas de mirtilo cv. 'Climax' através de microestaquia. Ciência Rural, Santa Maria, v.37, n.5, p.1446-1449, 2007. Disponível em: <http://www.scielo.br/scielo.php?pid=S0103-8478200 $7000500036 \&$ script $=$ sci arttext\&tlng $=$ pt $>$. Acesso em: 20 abr. 2011. doi: 10.1590/S0103-84782007000500036.

VILLA, F. et al. Propagação de amoreira-preta utilizando estacas lenhosas. Ciência agrotécnica, Lavras, v.27, n.4, p.829-834, 2003. Disponível em: <http://www.scielo.br/pdf/cagro/v27n4/ v27n4a13.pdf>. Acesso em: 20 abr. 2011. doi: 10.1590/S141370542003000400013 .

ZIETEMANN, C.; ROBERTO, S.R. Efeito de diferentes substratos e épocas de coleta no enraizamento de estacas herbáceas de goiabeira, cvs. paluma e século XXI. Revista Brasileira de Fruticultura, Jaboticabal, v.29, n.1, p.31-36, 2007. Disponível em: <http:// www.scielo.br/scielo.php? script $=$ sci_arttext $\&$ pid $=S 0100$ $29452007000100009 \& \operatorname{lng}=$ pt\&nrm=iso $>$. Acesso em: 7 maio, 2011. doi: 10.1590/S0100-29452007000100009. 